\title{
Periurbanidad, desigualdad
}

\author{
y segregación en \\ San Luis Potosí, 1990-2010
}

Adrián Moreno Mata*

Anahí Cárdenas Nielsen ${ }^{* *}$

Ricardo Villasis Keever ${ }^{* * *}$

De manera exploratoria, en este artículo se analizan las relaciones, siempre complejas y dinámicas, entre los procesos periurbanos, la desigualdad social y la segregación residencial en la zona metropolitana de la ciudad de San Luis Potosí, SLP. Además se explora la conexión con el surgimiento del modelo de ciudad cerrada e insegura, caracterizado por la modalidad de urbanización defensiva y el desarrollo de urbanizaciones cerradas. El marco territorial de referencia del estudio incluye el sector sur-poniente de la ciudad, ubicado en la franja periurbana.

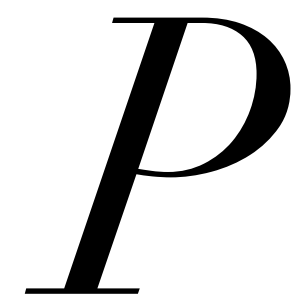

Categorías CONGeptuales

RÁCTICAMENTE ENTODO el mundo las actuales ciudades están inmersas en procesos contradictorios; recienten los impactos de fenómenos como la globalización cuya fuerza rebasa todas las fronteras. Los citadinos adoptan estilos de vida similares; los go-

* Profesor-investigador de la Facultad del Hábitat de la Universidad Autónoma de San Luis Potosí, México.

** Alumna de la maestría en Ciencias del Hábitat de la Facultad del Hábitat de la Universidad Autónoma de San Luis Potosí, México.

*** Profesor-investigador de la Facultad del Hábitat de la Universidad Autónoma de San Luis Potosí, México. biernos y desarrolladores inmobiliarios impulsan modelos urbanos que morfológicamente se imponen como un patrón generalizado. Las ciudades se hacen cada vez más fragmentadas y dispersas. Ligado a la fragmentación, se observa la presencia creciente de una mayor segmentación y segregación socio-residencial que hace a las ciudades más complejas: la interacción e integración de los grupos sociales se ve limitada por el surgimiento de la homogeneidad socioeconómica, que a su vez impone formas sociales y espaciales específicas, en las que ciertos grupos sociales se autoexcluyen del resto y se concentran en áreas residenciales acotadas, bajo supuestos como la inseguridad, el miedo y la urbanización defensiva (véase figura I). 


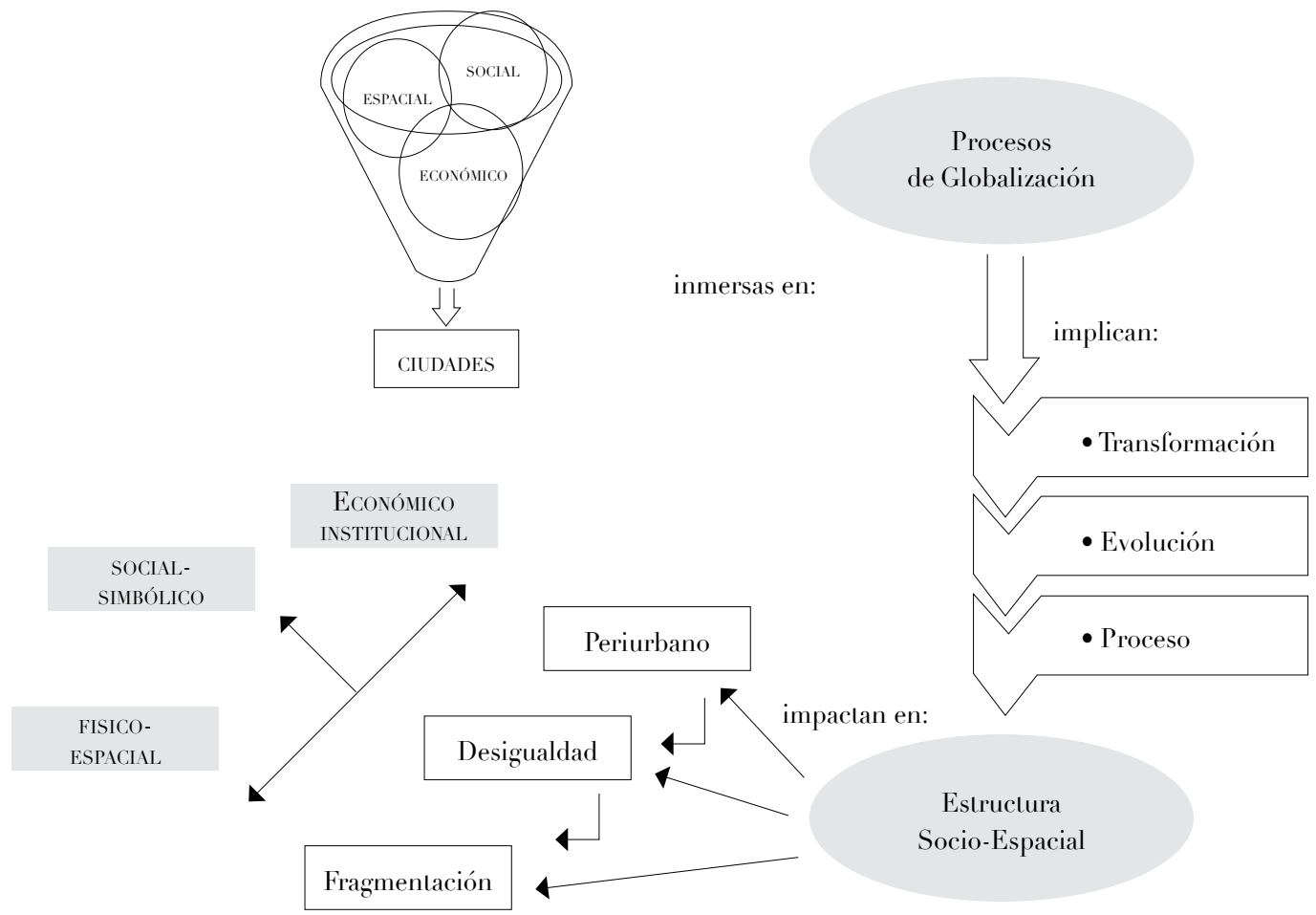

Fuente: Elaboración propia.

La fragmentación socioespacial constituye el patrón demográfico y espacial dominante en las ciudades contemporáneas y se refiere a procesos de desigualdad que tienden a generar dos grandes grupos de personas en dos contextos: en el marco de la globalización' los ganadores y los perdedores, y dentro de la exclusión socioeconómica y espacial ${ }^{2}$ los de adentro y los de afuera.

El efecto multidimensional de este proceso es de tal magnitud que alcanza la esfera de la planeación y gestión de la ciudad, la desintegración espacial de las ciudades, la ausencia de cohesión social y, eventualmente, la emergencia de un nuevo modelo o estilo de vida basado en la construcción en unidades independientes, además de la organización de la vida cotidiana hacia adentro (intramuros) y el desarrollo de nuevos guetos y enclaves urbanos.

Las ideas sobre guetos, antiguetos e hiperguetos planteadas por Löic Wacquant en su obra seminal Los condenados de la ciudad siguen vigentes en sus publicaciones más recientes. ${ }^{3}$ En ellas muestra que las tendencias de polarización y segregación residenciales en las ciudades observan ciertas diferencias y especifici- dades; en particular, destaca el comportamiento de estos procesos cuando analiza el caso de las ciudades estadounidenses (gueto negro) y lo compara con las ciudades europeas (antigueto francés). ${ }^{4} \mathrm{En}$ ambos casos muestra las especificidades que el lugar y la cultura, entre otros factores, imponen para hacer más o menos impenetrables (guetos norteamericanos, por ejemplo) o más permeables las fronteras intraurbanas (antiguetos europeos). También ilustra el paso del gueto al antigueto y al hipergueto como un proceso secuencial casi lógico.

Sin embargo, en las ciudades latinoamericanas las tendencias de estos fenómenos no necesariamente siguen estas etapas. Como señala Gentili, en muchas de las grandes y medianas ciudades de la región se observa una inversión de este modelo: pareciera que el proceso seguido fue el paso de ciudades más permeables (antiguetos) a guetos o nuevos guetos urbanos, en lo que se han constituido los llamados cotos, fraccionamientos o urbanizaciones cerrados. ${ }^{5}$ Autores como Janoschka, enfatizan la necesidad de mostrar el avance de este modelo de ciudad cerrada: $i$ ) el aumento creciente de las urbanizaciones cerradas, sobre todo en el área 
suburbana; ii) la descentralización de núcleos de empleo y actividad económica asociados a ello, y iii) la conformación de nuevos centros y subcentros urbanos vinculados a una dinámica propia, fragmentada y conectada al desarrollo de megaproyectos urbanos, a la creciente construcción de centros comerciales y de infraestructura de comunicación; el aumento de vías de rápida circulación - ejes referenciales para el crecimiento espacial - se asocia también con la creciente construcción de grandes desarrollos residenciales para estratos socioeconómicos altos y medio altos. ${ }^{6}$

En este modelo, Janoschka y Glasze ponen en evidencia la transformación gradual de las ciudades latinoamericanas de la estructura en cuña desarrollada previamente - hasta los años setenta y un poco los ochenta - en la periferia urbana y su reemplazo por estructuras insulares (islas de riqueza, producción, consumo y precariedad) que se superponen a los ejes radiales y sectoriales de los modelos anteriores o bien se desarrollan a partir de ellos.7 El carácter marcadamente insular de las nuevas formas urbanas resalta la tendencia hacia una ciudad segregada y dividida: la "ciudad de islas" o "ciudad archipiélago", como le denominan algunos autores. Ésta se caracteriza por el crecimiento y dispersión de fragmentos urbanos no integrados entre sí.

El esquema se vuelve aún más complejo si se considera que el fenómeno de las urbanizaciones cerradas en las ciudades tiene nexos importantes con una multiplicidad de factores económicos, sociales, culturales, políticos o de gestión, entre otros. Asimismo, se observa una importante tendencia a que las urbanizaciones cerradas se localicen en áreas o sectores muy particulares de la ciudad, entre los que destaca el periurbano o la periferia urbana. A su vez, el periurbano está ligado a otras nociones, como dispersión urbana, suburbanización y rururbanización, entre otros procesos que caracterizan a las ciudades (véase figura 2).

FIgURA 2

Identificación del problema de investigación: las urbanizaciones cerradas y sus relaciones

PROBLEMA DE INVESTIGACIÓN: RELACIONES ENTRE PROCESOS

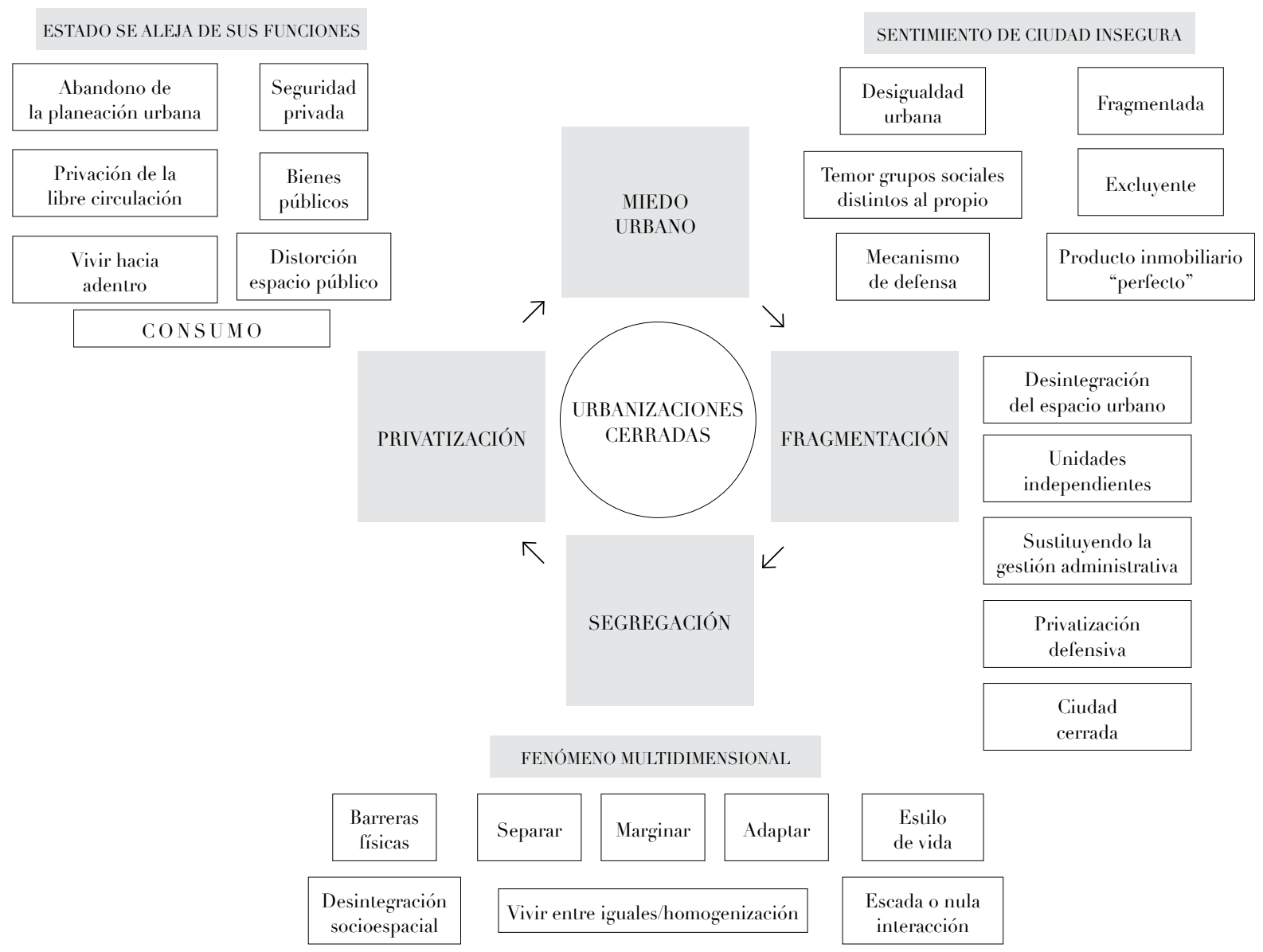

Fuente: Elaboración propia. 
Estas denominaciones que se utilizan para describir o explicar la expansión en los bordes urbanos comienzan a utilizarse en Estados Unidos a partir de los años setenta pero ya se manifestaban masivamente a partir de la segunda posguerra mundial como procesos socioespaciales también acompañados e incentivados por el zoning urbano, la traza de las autopistas y el uso masivo del automóvil como medio de transporte, conformando el nuevo estilo de vida de las familias acomodadas estadounidenses, el llamado american way of life. En Latinoamérica este fenómeno se consolida a partir de los años noventa en numerosas ciudades del centro y sur del continente, obligando a una refuncionalización del suburbio para llegar a una urbanización más completa en la funcionalidad, no sólo por la oferta de suelo urbano, sino también por la demanda de los habitantes de la nuevas urbanizaciones para mitigar la fricción del desplazamiento cotidiano a la ciudad central o los flujos origen-destino del hogar al trabajo.

Las ciudades latinoamericanas, y por supuesto mexicanas, se han ido acercando a un modelo de imbricación de la aglomeración física, la descentralización, la re-centralización, la desterritorialización y la re-territorialización; en suma, a una nueva resignificación de los espacios y sectores de la ciudad, en los que el periurbano ha derivado de una aglomeración inducida por el mercado del suelo y la vivienda, tanto a nivel de la oferta como de la demanda: nuevos espacios geográficos caracterizados por ser cuasi-ciudades y cuyo punto distintivo es la ciudad cerrada para diferenciarse, sea por estatus, por miedo a la inseguridad o por ambos. En este contexto, el trabajo analiza de manera exploratoria las relaciones, siempre complejas y dinámicas, entre los procesos periurbanos, la desigualdad social y la segregación residencial en la zona metropolitana de San Luis Potosí (ZMSLP); en el análisis se utiliza el paradigma de la ciudad cerrada e insegura y su contraparte, la ciudad inclusiva o incluyente. ${ }^{8}$

\section{Marco territorial de referencia}

La ZMSLP se localiza en la región centro del estado de San Luis Potosí (véanse figuras 3 y 4). Es sede de uno de los centros coloniales y turísticos más importantes del país; alberga a las dependencias del gobierno estatal y a la mayoría de los campus educativos de la entidad. Para 20ıо contaba con 955,753 habitantes, lo que la ubica como la décima ciudad más poblada de Méxi- co. ${ }^{9}$ La aceleración del crecimiento poblacional, junto a la expansión física, se produjo de manera predominante a lo largo de la segunda mitad del siglo xx. Este fenómeno ha sido acompañado por la adición de áreas pertenecientes al municipio conurbado de Soledad de Graciano Sánchez y la ampliación de su área de influencia hacia otras áreas rururbanas. De ig6o a r99o, la ZMSLP ha multiplicado tres veces su población y casi ocho veces su superficie, $y$ ha ocupado nuevos territorios tanto en el municipio central - San Luis Potosícomo en el municipio conurbado más antiguo, Soledad de Graciano Sánchez, donde el crecimiento ha sido más intenso, sobre todo a partir de ig8o. Además de las delegaciones de Bocas, Villa de Pozos y La Pila, y la localidad de Escalerillas, en el municipio de San Luis Potosí, el área urbanizada comienza a extenderse hacia otros municipios cercanos, destacando entre ellos los de Cerro de San Pedro, Soledad de Graciano Sánchez y, más recientemente, el de Villa de Reyes, hacia donde se localiza el parque industrial que concentra el mayor clúster automotriz de la región.

¡La evolución socioespacial de la Zona Metropolitana de San Luis Potosí siguió, desde sus orígenes hasta mediados del siglo pasado, un modelo de crecimiento predominantemente monocéntrico y concéntrico, de carácter radial-sectorial entre los años sesenta y ochenta, y de tipo policéntrico hacia finales del siglo Xx y principios del XXI. ${ }^{\circ}$

En la actualidad, este modelo se ha transformado, siendo aún más complejo a raíz del impacto de la globalización y otros procesos emergentes, como la fragmentación urbana, la segregación residencial y el desarrollo del modelo urbanístico y arquitectónico de las comunidades o urbanizaciones cerradas. Este modelo comienza a consolidarse en la etapa reciente, generando enclaves residenciales para estratos socioeconómicos altos y medios altos, asociados al desarrollo de nuevos polos de empleo y de servicios, que a su vez agudizan los patrones de la segregación y exclusión socioespacial.

A partir de la década de los noventa, la pauta de crecimiento urbano en la ZMSLP observa un continuo proceso de extensión de la superficie urbana construida hacia el poniente de esta zona metropolitana con construcciones para el sector económico preponderante, especialmente fuera de los límites urbanos. Después de 1997 este crecimiento urbano superó el anillo periférico de la ZMSLP, lo cual ha ocasionado diversos problemas expresados en diferentes dimensiones, que van desde transformaciones de la dinámica demográ- 
fica y de las preferencias en la localización residencial, hasta cambios de uso del suelo y de la actividad económica, el crecimiento espacial y residencial, y el de- sarrollo de sectores urbanos caracterizados por la marginación y exclusión respecto a los bienes y servicios de la ciudad, es decir, los nuevos guetos urbanos.

Figuras 3 Y 4

Ubicación geográfica y evolución urbana de la zMSLP
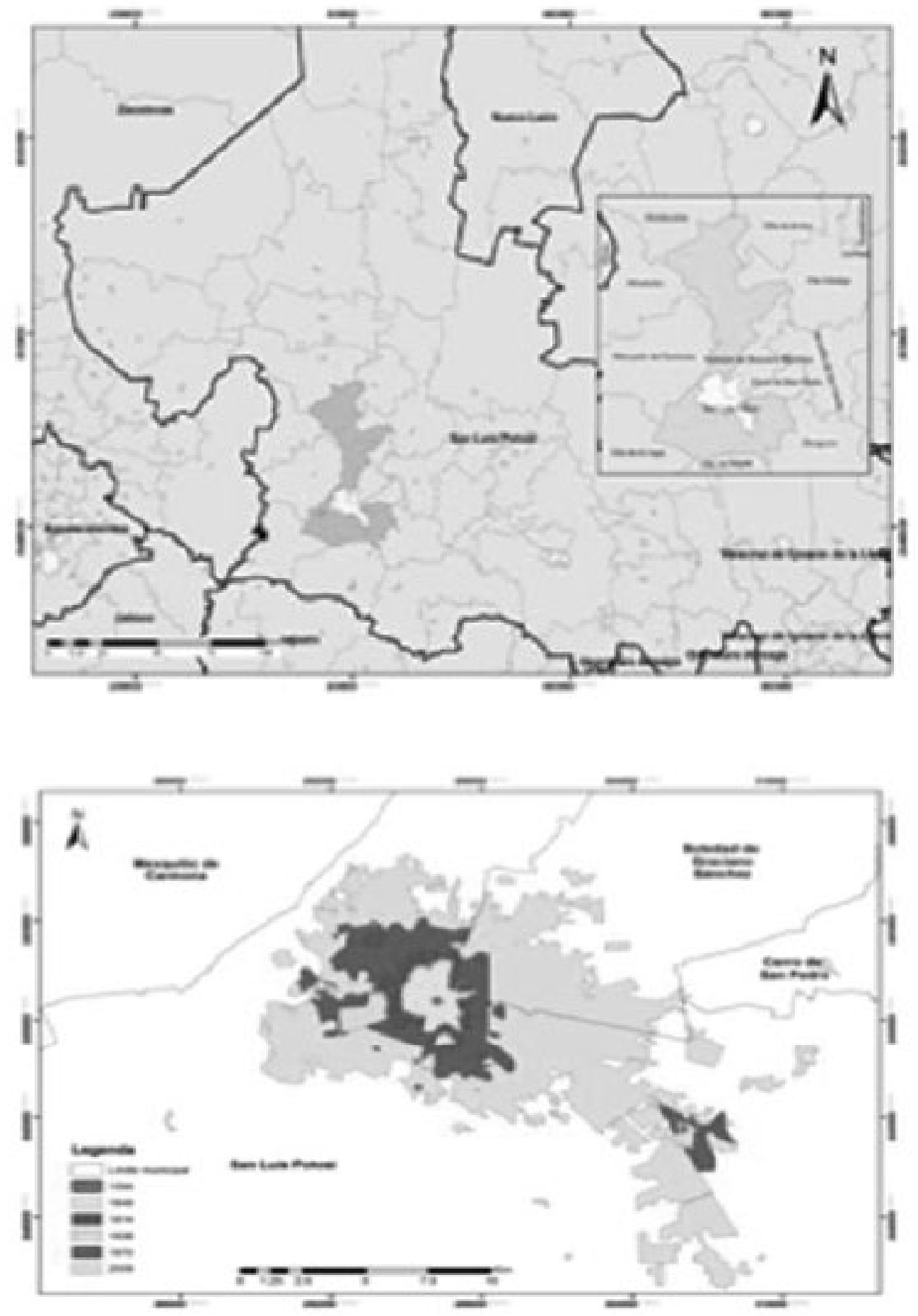

Fuente: Moreno (2010). 
El análisis del comportamiento de las variables de ingreso por estratos socioeconómicos a nivel de área geoestadística básica (AGEB) en relación con las condiciones de habitabilidad (grado de hacinamiento y deterioro de la vivienda) y dotación de los servicios básicos de agua potable y drenaje en el interior de las viviendas, muestra que prácticamente ninguno de los sectores de la ZMSLP observa una total homogeneidad respecto a esos indicadores (véanse figuras 5 a 8 ).

Como puede observarse, se produce un patrón diferenciado de consolidación residencial, que revela, a su vez, por lo menos tres niveles: medio alto, medio bajo y bajo. Por el contrario, en las áreas o colonias periurbanas localizadas al norte y sur de la mancha urbana, se observa claramente la localización de clústers de pobreza urbana.

\section{Caso de estudio: urbanización del sector sur-poniente}

El sector poniente de la ZMSLP es denominado como la zona Lomas-Tangamanga en la zonificación que contemplan los planes de desarrollo urbano del munici- pio de San Luis Potosí. Este sector se delimita originalmente tanto en el sur como en el poniente por el Anillo Periférico, mientras que al norte es limitado por el Boulevard del Río de Santiago, y al oriente por la Avenida Muñoz, una de las vialidades más conflictivas de la ciudad (véanse figuras 9 y ro).

En la década de los años noventa, la población de la ciudad central y de otros sectores, como es el caso del sur-poniente, crecieron a una tasa promedio anual inferior al de la zona metropolitana en su conjunto. En el caso de estudio, entre otros factores, esto se debe a que al inicio del periodo, la zona sur-poniente contenía una menor proporción de área urbanizada y, a la vez, una superficie importante de áreas no urbanas, ubicadas de manera predominante en el área de recarga natural del acuífero principal, en particular en los terrenos correspondientes al ejido La Garita de Jalisco. En este sentido, el proceso de ocupación de ese sector de la zona metropolitana a lo largo de la década, implicó cambios importantes en términos de las tasas de ocupación del suelo, así como en la modificación de la densidad poblacional de la zona.

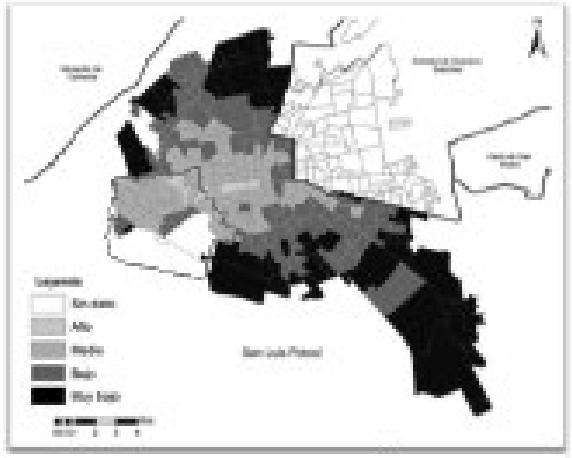

Tipo de vivienda

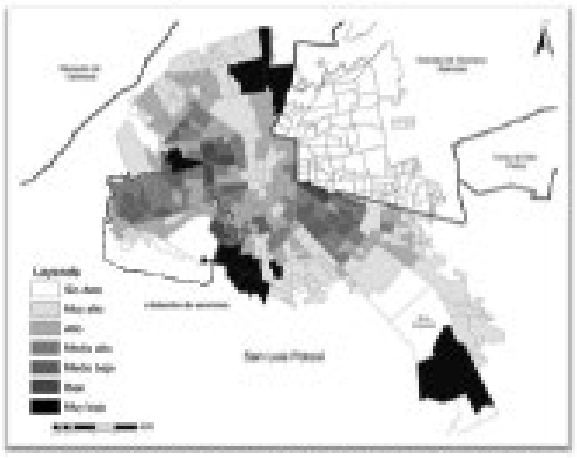

Participantes por grado de dotación se servicios

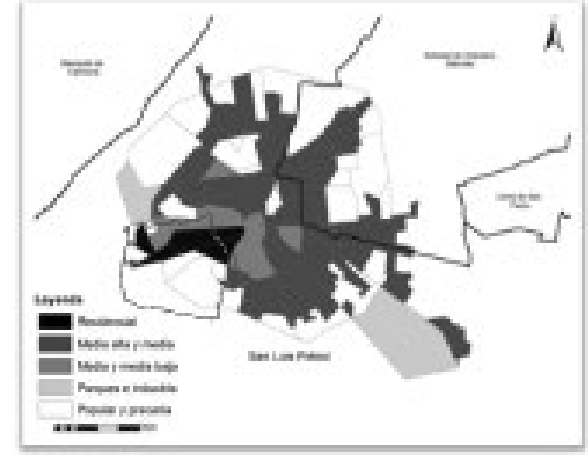

Estratificación

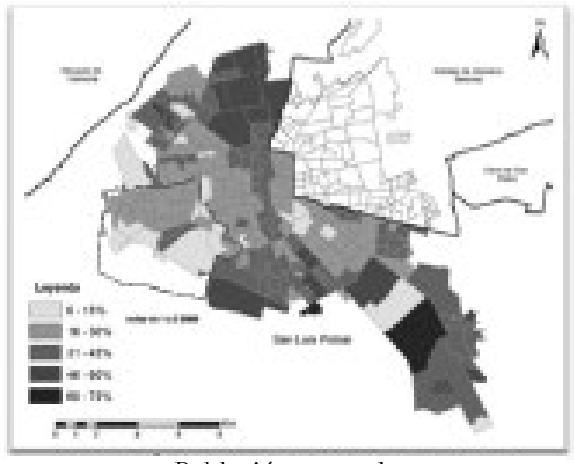

Población ocupada que recibe de $1 \mathrm{~A}$ a 2 SMM

Fuente: Elaboración propia con base en el programa Geoda, 20I/. 


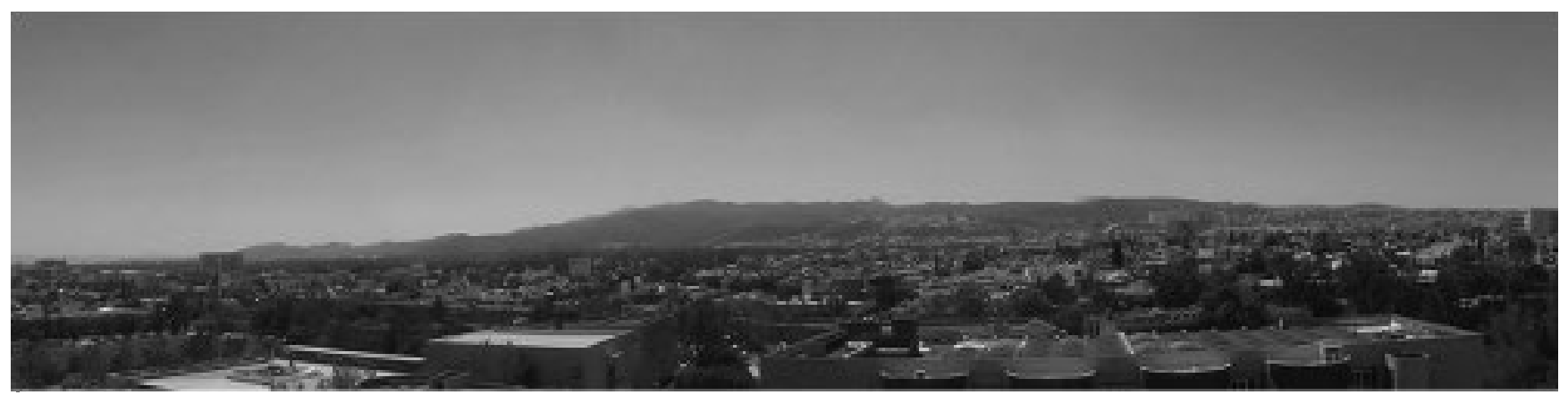

Fotografía: Adrián Moreno.

Este sector concentra lo mejor del equipamiento y la infraestructura urbana, que elevan las condiciones de habitabilidad, servicios e infraestructura de la ciudad. La megaurbanización sur-poniente abarca una superficie cercana a las 3,80o hectáreas, es decir, 2I.4 por ciento del total de la mancha urbana, con una población cercana a los 6o,ooo habitantes. Comprende en la actualidad 56 colonias, fraccionamientos y subsectores urbanos; I8 de ellos ya existían en 2005 y 38 han sido como áreas urbanizadas de nuevo crecimiento, bajo el concep- to de urbanizaciones cerradas, en el periodo comprendido entre 2005 y 2014 (véase figura II).

Las urbanizaciones o desarrollos urbanos contenidos en la megaurbanización sur-poniente abarcan una gran variedad de modalidades y tamaños: megadesarrollos cercanos a las 5oo hectáreas, barrios cerrados, fraccionamientos campestres y clubes de golf. Todos estos núcleos urbanos se localizan a una distancia promedio de 20 a 30 minutos del centro de la ciudad. En este sentido, las modalidades de desplazamiento coti-

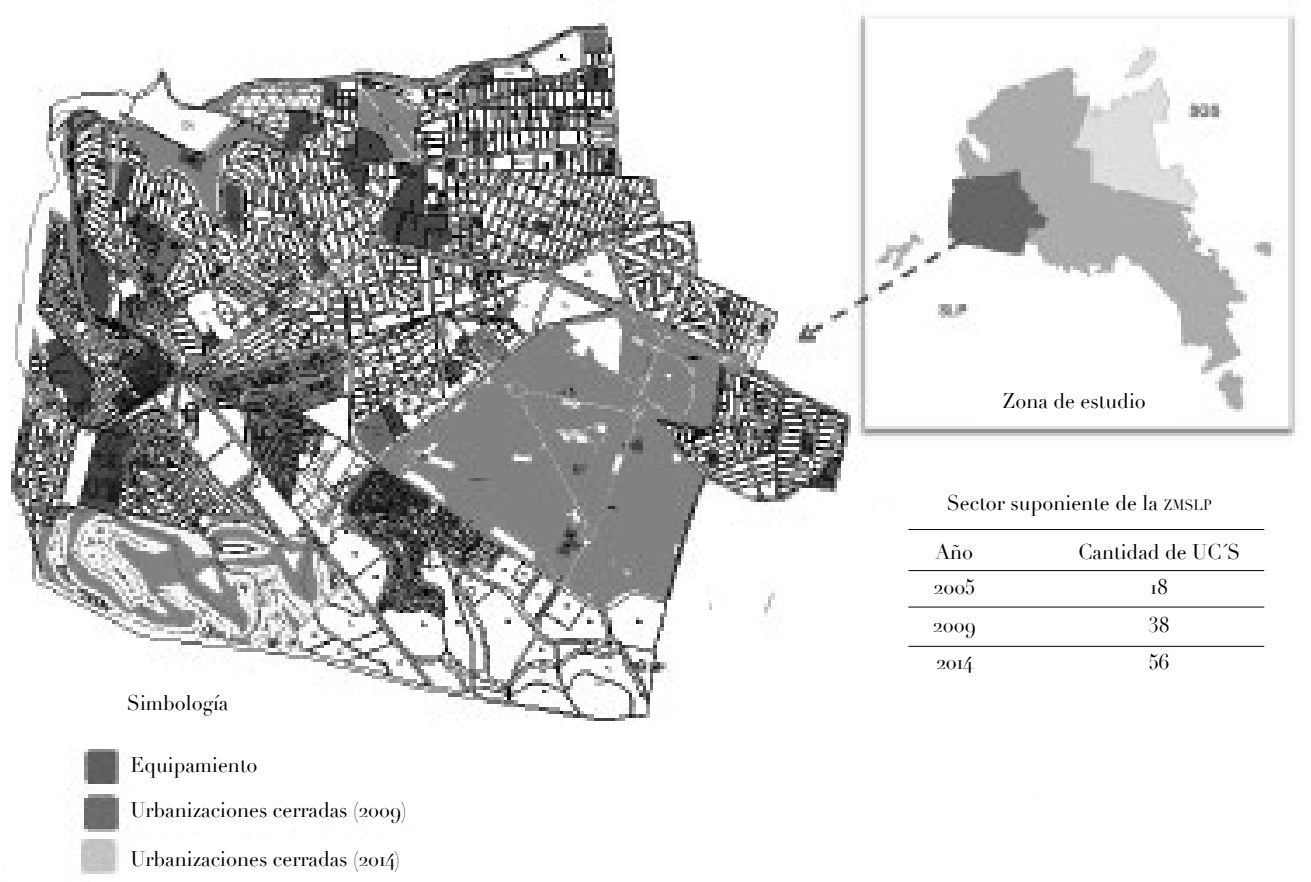

Fuente: Elaboración propia. 
diano desde esos lugares a otros puntos de la ZMSLP establecen un punto de ruptura en cuanto al modo de vida, el uso intensivo del automóvil y otras prácticas relacionadas con la movilidad residencial y el empleo.

\section{Conclusiones: tendencias de un MOdElo} DE CIUDAD DESIGUAL Y EXCLUYENTE

La consolidación urbana del sector sur-poniente de la ZMSLP puede explicarse a partir de diversos factores causales y efectos, que van desde el orden político y de gestión pública hasta los de naturaleza económica y ambiental. Las consecuencias de este nuevo patrón espacial y socioeconómico se relacionan con distintas tendencias: i) profundización de la brecha entre habitantes ricos y pobres en la ciudad, ii) reorganización de la estructura socioespacial, que agudiza los fenómenos de segregación residencial y fragmentación urbana;iii) nueva redistribución espacial de población, actividades económicas y satisfactores urbanos (léase equipamiento y megaproyectos urbanos); iv) generación de nuevas relaciones espaciales dentro de la región metropolitana, que reemplazan la estructura tradicional de orden concéntrico o sectorial por la estructura policéntrica y fragmentada, pero también por una organización socioespacial regida por factores inéditos, como la percepción social (el miedo, la inseguridad y la victimización asociada a los delitos).

La reestructuración socioespacial de la ciudad se organiza a distintas escalas: la escala macro de la ciu- dad como un todo, la escala meso o intermedia a nivel de grandes sectores urbanos (tradicionales y nuevos) y la escala micro de barrios, colonias, fraccionamientos $y$, por supuesto, las nuevas configuraciones urbanas (urbanizaciones o comunidades cerradas). Sin embargo, si se analizan a mayor detalle los sistemas de gestión y gobernanza involucrados en estas tendencias del desarrollo urbano, se observan algunas contradicciones. Por un lado, una creciente interacción entre el Estado y otros agentes económicos locales, en particular el sector inmobiliario, a través de los instrumentos de gestión y planeación urbana locales, en la creación de condiciones que favorezcan el desarrollo de un nuevo modelo de ciudad: la ciudad-empresa o la ciudad eficiente; por el otro, una creciente incapacidad de los aparatos de planeación y gestión de la ciudad para impedir el desarrollo de un modelo urbano dual, en el que destaca la contraposición de nuevos espacios y configuraciones urbanas con una ubicación y potencial más ventajosos en términos de participación y conexión con los circuitos económicos y culturales y de su articulación a mercados altamente competitivos regidos por el principio de la rentabilidad privada, frente al deterioro y precarización de otros sectores urbanos y de la población, en los que se agudiza la presencia y extensión de los procesos de segregaciónfragmentación-exclusión socioespacial. En este sentido, no se aprecian intentos por compensar los costos sociales, económicos y ambientales derivados del nuevo modelo de ciudad y la reestructuración económica y espacial a escala urbana.

\section{$-\operatorname{notas} \cdot-$}

' Garza, Gustavo (1999), "Globalización económica, concentración metropolitana y políticas urbanas en México”, Estudios Demográficos y Urbanos, vol. ı4, núm. 2, pp. 269-3Іі.

2Malizia, Matilde y Pablo Paolasso (2009), "Countries y barrios privados en Yerba Buena, Gran San Miguel de Tucumán, Argentina: nuevas formas de expansión urbana", Estudios Demográficos y Urbanos, vol. 2/, núm. 3, pp. 583-6ıィ.

${ }^{3}$ Wacquant, Löic (2014), "Ciudad, inclusión social y educación”, en Jordi Martí Galbis (coord.), Monográfico AICE, XIII Congrés Internacional de Ciutats Educadores 2014, Barcelona, Gobierno de Catalunya.

${ }^{4}$ Idem.

${ }^{5}$ Gentili, Pablo (2014), "Conferencia inaugural", XIII Congrés Internacional de Ciutats Educadores 20I4, I3 de noviembre de 2014, Barcelona, Gobierno de Catalunya.

${ }^{6}$ Janoschka, Michael (2003), "Nordelta, ciudad cerrada. El análisis de un nuevo estilo de vida en el Gran Buenos Aires", Scripta Nova, vol. 7, núm. I 46 , p. I2I.
7 Janoschka, Miguel y Georg Glasze (2003), "Urbanizaciones cerradas: un modelo analítico", Cuadernos de Trabajo, Santiago de Chile, Ministerio de Educación y Ciencia.

${ }^{8}$ Balbo, Marcelo (2003), "Ciudad inclusiva", en M. Balbo et al., La ciudad inclusiva, Cuadernos de la CEPAL, núm. 88, Santiago de Chile, CEPAL/Cooperazione Italiana, pp. 29-58.

9 Consejo Nacional de Población (CONAPO) (2005), Estimaciones del Grupo Interinstitucional Base CONAPO, XII Censo General de Población y Vivienda 200o, II Conteo de Población y Vivienda 2005, disponible en http://www.inegi.org.mx/est/ contenidos/espanol/metodologias/otras/zonas_met.pdf

${ }^{\circ}$ Moreno, Adrián (1989), El proceso de producción del espacio en la ciudad de San Luis Potosí: el problema de la vivienda, México, El Colegio de México, p. 2ı9; Moreno, Adrián (2010), "Utopía y reconceptualización del modelo urbano mexicano. Enfoques alternativos en el estudio de la centralidad y las nuevas centralidades: el caso de la zona metropolitana de San Luis Potosí”, Revista de Arquitectura, Diseño y Urbanismo, núm. 7, pp. ı8o-ig5̆. 